\title{
Supervivencia a largo plazo de los injertos grasos
}

\section{Long-term survival with fat grafiing}

Planas, J.*, Cervelli, V.**, Pontón, A.***, Planas, G.*

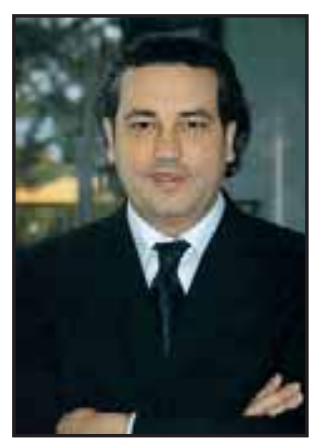

Planas, J.
Resumen

Presentamos varios casos de pérdida de volumen de diferentes etiologías y en distintas regiones corporales y faciales tratadas mediante injertos de tejido graso autólogo según la técnica de lipoestructura. En ningún caso se realizó sobrecorrección del defecto en ningún caso. La evolución con un seguimiento máximo de 7 años y mínimo de 1 año no mostró disminución del volumen obtenido en el acto quirúrgico en la gran mayoría de los casos. Debido a los resultados obtenidos creemos que el injerto de grasa autólogo es el método de elección para restaurar volúmenes con fines estéticos o reconstructivos.
Palabras clave Injerto graso autólogo. Lipoestructura.

Código numérico 15841
Key words Autologous fat graft. Lipostructure.

Key words Autologous fat graft. Lipostructure.

Código numérico 15841
Volume loss in several facial and body areas was treated by means of autologous fatty tissue grafts with lipostructure technique. There were no cases of overcorrection.

The patients' course, with a maximum follow-up of 7 years and a minimum of 1 year did not evidence any loss of the surgically restored tissue volume in the majority of cases.

The above results suggest that autologous fat grafts are the method of choice to restore volume for both cosmetic and reconstructive purposes. 


\section{Introducción}

La modificación del contorno de partes blandas mediante el injerto de grasa autólogo se remonta al año 1893, cuando Neuber lo realiza con relativo éxito (1). En los años siguientes Lexer remodela secuelas de fracturas de arcada zigomática con grasa autóloga (2).

Poder utilizar la grasa del propio paciente como material de elección para restaurar volúmenes ha hecho que se describan distintas formas de obtención de la misma; con o sin infiltración de la zona donante, con distintas presiones negativas de succión; distintos tipos de procesamiento de la grasa extraída ya sea mediante lavado, colado, decantación o centrifugación de la misma y otras tantas formas de implantarla según el plano utilizado, el grosor de los implantes, la separación de los mismos entre sí, etc., con resultados muy dispares.

En 1950 Peer reporta una reabsorción del tejido graso autólogo injertado cercana al 50\% (3). A su vez, Matsudo y Toledo observan una reabsorción del $20 \%$ al 50\% de los injertos grasos realizados, por lo que realizan sobre-correcciones del $35 \%$ del volumen necesario para corregir el defecto (4). Illouz en 1988 publica una supervivencia de sólo el $20 \%$ de la grasa y aconseja sobrecorregir (5). Carpaneda (1994) refiere supervivencia únicamente del $40 \%$ del implante graso, siempre y cuando el diámetro del filamento injertado sea menor de $3 \mathrm{~mm}$., ya que demuestra que el injerto sobrevive por imbibición plasmática hasta $1.5 \mathrm{~mm}$. del borde vascularizado, motivo por el que aconseja dejar espacio entre los filamentos (6).

Otros autores han tenido mayores tasas de supervivencia en sus series: Chajchir publica en 1996 un articulo en el que presenta unos resultados a largo plazo muy satisfactorios (7).

Coleman describe en una serie de publicaciones en los 90, su sistemática para realizar el implante del tejido graso autólogo con alta supervivencia a largo plazo $(8-11)$.

Guerrerosantos demostró experimentalmente la supervivencia de la grasa autóloga implantándola de forma intramuscular en ratas (12), y publica en 2000 su experiencia de 16 años con este tipo de injerto, tanto como complemento de relleno en cirugía facial como en pacientes con atrofia hemifacial progresiva causada por el Síndrome Parry-Romberg, con excelentes resultados en ambas indicaciones (13).

Por su parte, Erol (14) considera que un "cocktail" de grasa, dermis y fascia, aumenta la supervivencia del injerto en comparación con el injerto únicamente de grasa y reporta una experiencia de 10 años con su técnica.
Quizás debido a esa gran disparidad de técnicas, y sobretodo de criterios de supervivencia de la grasa, hay autores que no creen en la viabilidad del injerto graso y han recurrido a la utilización de diversos materiales aloplásticos como silicona o metacrilato, no exentos de complicaciones como la extrusión o reacción a cuerpo extraño.

Material y método

Hemos utilizado la técnica de lipoestructura según describe Coleman con fines estéticos y reconstructivos en distintas regiones corporales y faciales.

Se realizaron injertos de grasa autólogos en 140 pacientes, con un seguimiento máximo de 7 años y mínimo de 1 año, bajo anestesia local, epidural o general, dependiendo de la extensión de la zona a tratar.

La zona donante fue elegida en base a la cuantificación de la grasa existente en ella mediante el examen físico, a la necesidad de corregir algún exceso de volumen en dicha zona y a la cantidad de grasa que se precisaba para restaurar el volumen de la zona a rellenar siendo las zonas más frecuentemente cosechadas el abdomen, la región trocantérea y el muslo.

Para la obtención, procesamiento e infiltración del tejido graso se siguió el protocolo descrito por Coleman (8-11): el tejido graso se obtuvo con una cánula de aspiración de punta roma unida a una jeringa de 10cc. tipo Luer-lock, asegurando una baja presión negativa de aspiración para evitar traumatizar en lo posible los adipocitos. El diámetro interno de la cánula de extracción o infiltración debe ser igual al orificio de la jeringa que se esté utilizando para no dañar el tejido graso. La grasa extraída no se manipuló con técnicas de lavado o colado y se centrifugó a 3000 revoluciones por minuto (r.p.m.) durante 3 minutos.

La centrifugación de la grasa extraída divide en tres estratos su contenido: en el estrato superior queda el aceite (triglicéridos libres); en el estrato inferior, los fluidos y la sangre. Ambos estratos se descartan decantándolos y quedándonos, solamente con el estrato central que es la grasa pura, con posibilidades de sobrevivir una vez infiltrada en otra zona del organismo.

Para evitar el contacto de la grasa con el aire, lo que podría producir una lisis adipocitaria (15), se coloca una gasa bordeada en el émbolo de la jeringa hasta el momento de la implantación. Se utilizan adaptadores entre jeringas de $1 \mathrm{cc}$. y de $10 \mathrm{cc}$. cuando es necesario traspasar la grasa entre jeringas según la zona a infiltrar. Se obtienen de esta forma de 3 a $7 \mathrm{cc}$. de grasa pura por cada $10 \mathrm{cc}$. de material succionado.

Presentamos la técnica descrita para tratar diferentes inestetismos en una serie de casos reflejados 

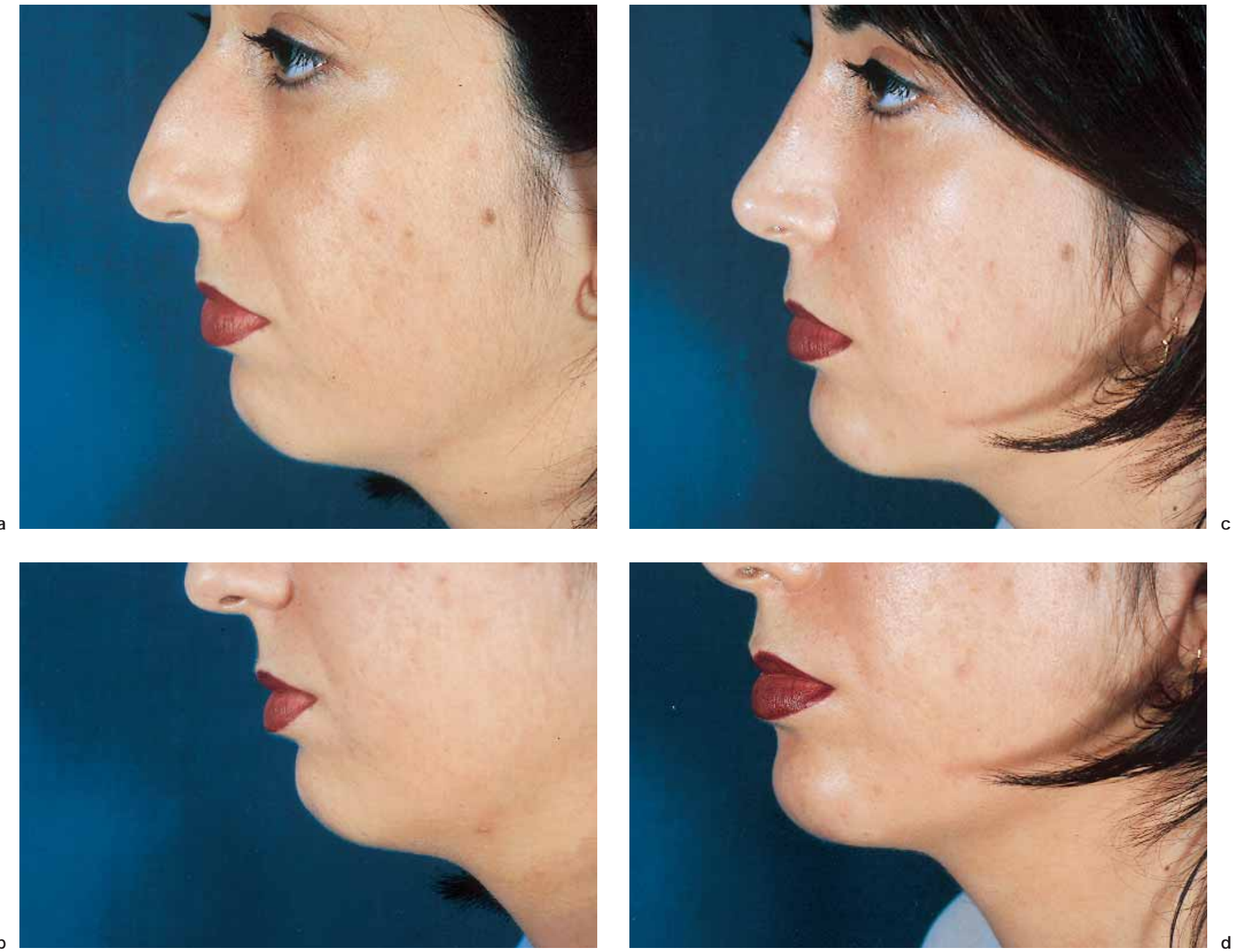

Figura 1. (a,b) Paciente de 22 años de edad con microgenia; (c, d) postoperatorio de 6 años de evolución tras una sola sesión de lipoestructura con inyección de $4 \mathrm{cc}$. de grasa autóloga.

Tabla I. Relación de casos

\section{INDICACION}

Depresión en dorso nasal

Hipogenia mentoniana

Hipogenia malar

"Ojeras"

Pérdida volumen en párpado superior

Rejuvenecimiento facial

Agenesia pabellón auricular

Depresiones en glúteos

Secuela fibromatosis desmoide juvenil

Cicatrices deprimidas

Secuela ginecomastia

Secuela sindrome compartimental

Secuela poliomelitis

Aumento de glúteos

Secuela accidente de tráfico
$\mathbf{N}^{\circ}$ CASOS

4

28

6

11

2

10

1

8

1

20

1

1

1

19

1
SESIONES

1

1

1

1

1

3

1

1

1

1
CC INFILTRACION

2-3 cc.

4-10 cc.

4-10 cc.

0,7-1cc x lado

$1 \mathrm{cc} x$ lado

$8-25 \mathrm{cc}$

$30 \mathrm{cc}$

8-150 cc

$140 \mathrm{cc}$

$70 \mathrm{cc}$

$12 \mathrm{cc}$

10-270 cc.

$40 \mathrm{cc} x$ lado

$105 \mathrm{cc}$

$350 \mathrm{cc}$

80-200 cc x glúteo

270-150 cc 

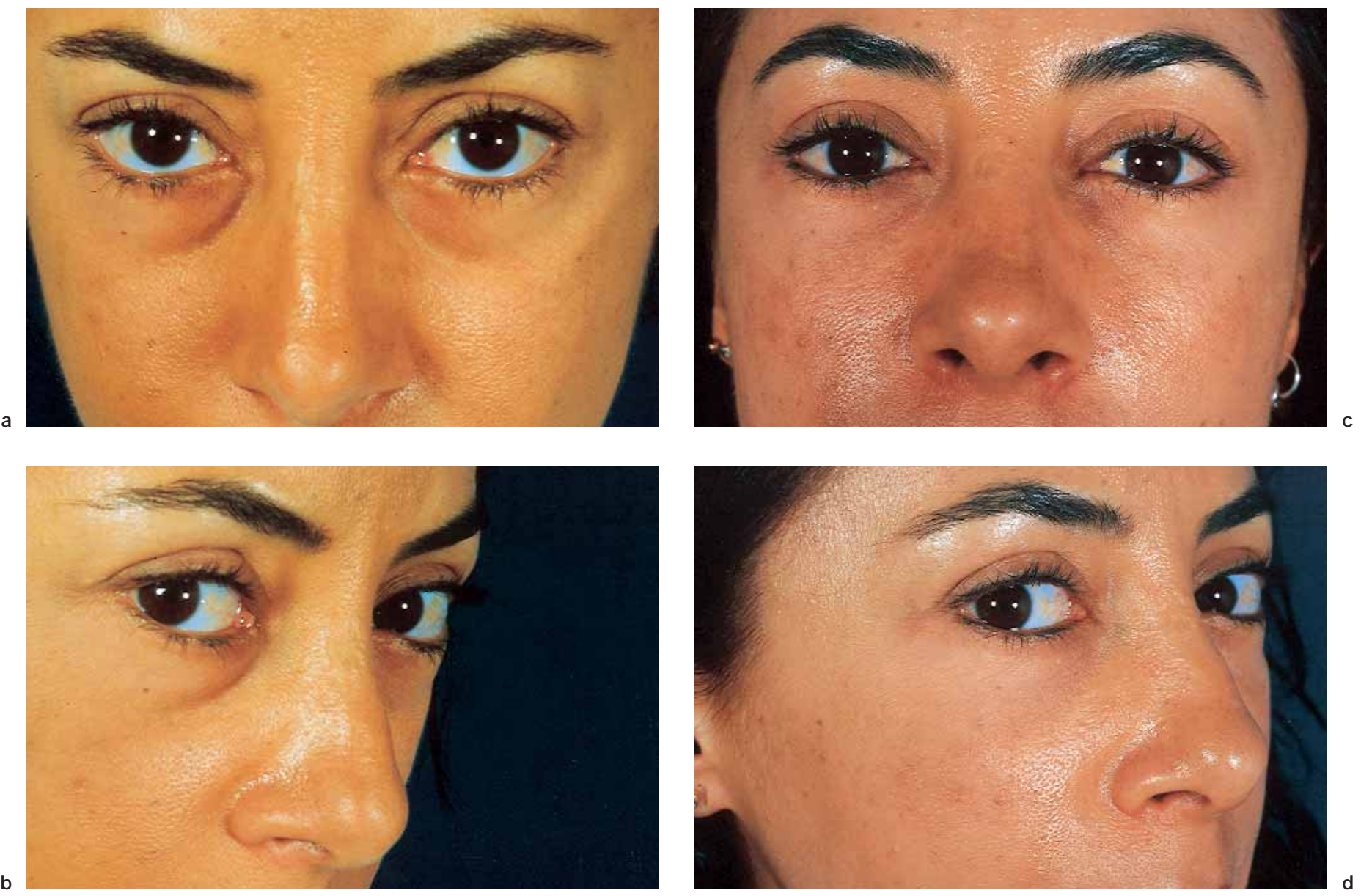

Figura 2. (a, b) Paciente de 36 años de edad con depresiones en surcos naso-yugales (c,d): postoperatorio a los 6 años tras una sesión de lipoestructura de 1cc. de grasa en cada párpado.

en la Tabla I: depresiones del dorso nasal posteriores a resecciones excesivas de éste durante procedimientos de rinoplastia (4 casos) infiltrándose entre 2 y $3 \mathrm{cc}$.; hipogenias mentonianas ( 28 casos) (Fig. 1) o malares (6 casos) infiltrándose de 4 a $10 \mathrm{cc}$; como tratamiento para depresiones marcadas a nivel del párpado inferior "ojeras" (11 casos) infiltrándose entre 0.7 y $1 \mathrm{cc}$. en cada párpado (Fig. 2); para corregir pérdidas de volumen en el párpado superior consecutivas a una blefaroplastia ( 2 casos) infiltrando 1cc. (Fig. 3); como tratamiento de rejuvenecimiento facial ( 10 casos) entre 8 y 25 cc.; para tratar una agenesia de pabellón auricular (1 caso) 30 cc; en depresiones glúteas ( 8 casos) infiltrándose entre $8 \mathrm{cc}$. y $150 \mathrm{cc}$; como tratamiento para realizar una reconstrucción secundaria a la resección de una fibromatosis desmoide juvenil cuya exéresis involucró la resección del músculo dorsal ancho conjuntamente con la escápula (1 caso) para lo cual se realizaron 3 sesiones con intervalos de 6 meses entre cada una de ellas e infiltrando $140 ., 70 \mathrm{cc}$ y finalmente $12 \mathrm{cc}$. (Fig. 4); en cicatrices deprimidas (20 casos) infiltrándose entre 10 y 270 cc..; para corregir una secuela de ginecomastia (1 caso) $40 \mathrm{cc}$. por lado; en una secuela de síndrome compartimental (1 caso) en el que se infiltró 105 cc.; para corregir una secuela de Poliomielitis ( 1 caso) $350 \mathrm{cc}$.; como tratamiento para aumento de glúteos (19 casos) entre 85 y 200 cc. por glúteo (Fig. 5) y por último para rellenar una severa perdida de sustancia en muslo consecutiva a accidente de tráfico ( 1 caso) donde se realizaron 3 sesiones infiltrando 270,150 y $50 \mathrm{cc}$. en intervalos de seis meses cada una (Fig. 6).

La grasa se colocó en todos los casos en diferentes planos intramuscular, subdérmico y subcutáneo, mediante dos incisiones de $1 \mathrm{~mm}$. alejadas por lo menos $1 \mathrm{~cm}$. de la zona a tratar, de forma que se crucen los múltiples pases que se realizan con la cánula por ambos abordajes y depositando implantes grasos de aproximadamente $3 \mathrm{~mm}$. en trayectos filamentosos de forma cilíndrica y de manera tal que exista una separación entre ellos para que sea posible su supervivencia (6).

En los casos en los cuales existía una cicatriz deprimida con adherencias a planos profundos, antes de realizar la infiltración del tejido graso se realizó liberación de los tejidos mediante utilización de cánulas disectoras con extremos cortantes en forma de V. La infiltración del tejido graso se realizó con cánulas 

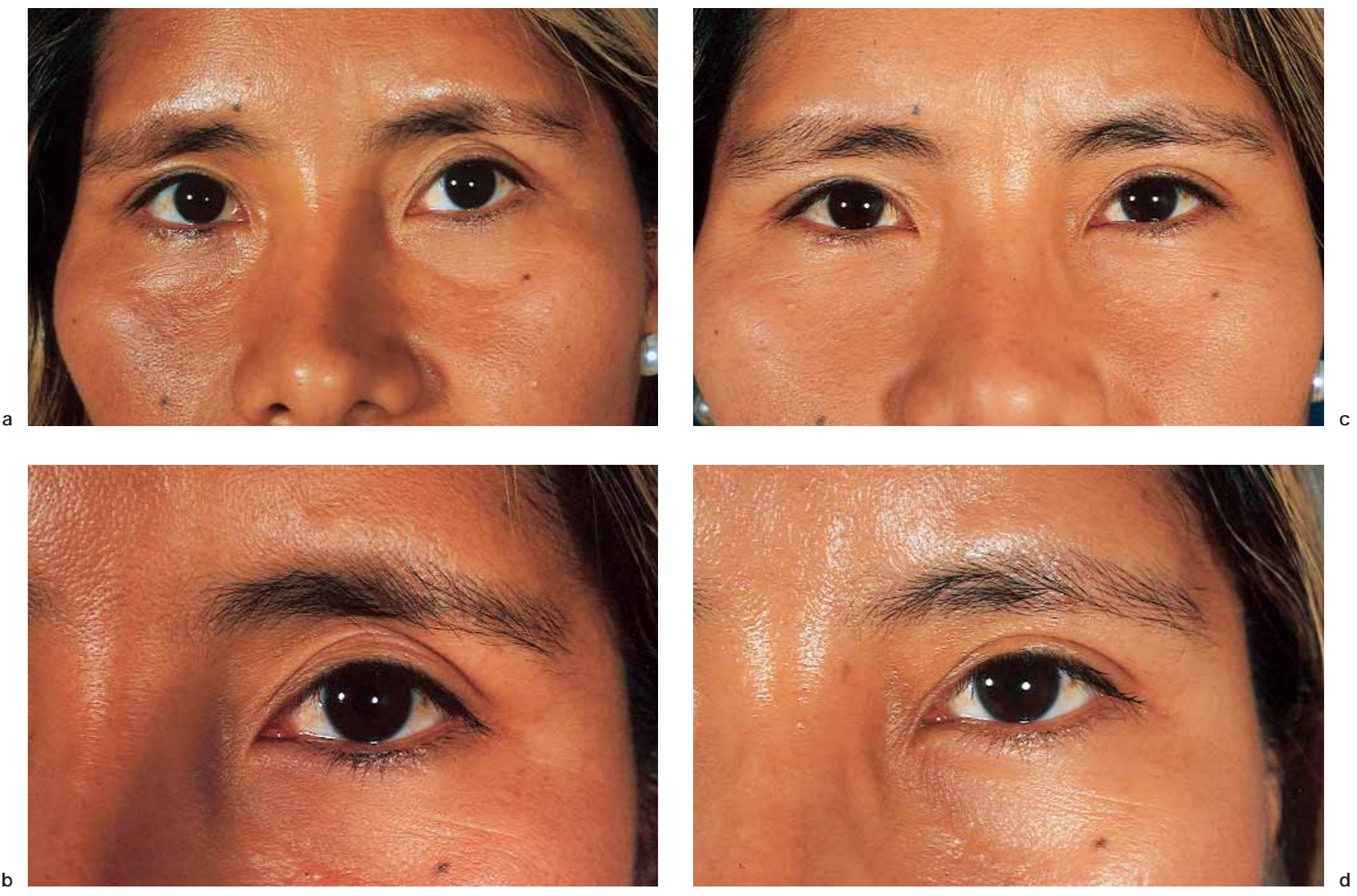

Figura 3. (a,b) Paciente de 33 años de edad con secuelas post blefaroplastía superior de párpado izquierdo. (c,d): corrección mediante liberación de la fibrosis de la zona e infiltración de 1cc. de grasa autóloga a los 7 años de evolución .

Tipo I de Coleman en zonas pequeñas, preferentemente en el rostro; Tipo II, la más utilizada con el orificio cercano a la punta y Tipo III, en zonas moderadamente fibrosas.

Después de restaurar el volumen deseado, sin realizar sobrecorrección en ningún caso, se exprimió digitalmente el orificio de entrada para eliminar todo acúmulo posible de tejido graso en dicha zona, que luego podría formar una pequeña deformidad.

La zona injertada se inmovilizó con esparadrapos durante 4 a 6 días.

El seguimiento se llevó a cabo al día siguiente del acto quirúrgico, a la semana, al mes, a los 3 meses y posteriormente cada año, mediante evaluación comparativa entre el pre y el postoperatorio de forma clínica y fotográfica.

\section{Resultados}

Durante el seguimiento realizado se observó que el volumen obtenido mediante el implante graso se incrementó a partir de los primeros días del postoperatorio, hasta aproximadamente los 30-35 días debido al edema causado por el acto quirúrgico en sí.
A partir de entonces el volumen vuelve a ser el mismo que habíamos logrado en el acto quirúrgico, manteniéndose constante durante el seguimiento realizado excepto en tres casos: dos de restauración de grandes volúmenes en los que fueron necesarias dos sesiones más y uno de depresión del dorso nasal en el que se optó por implantar hidroxiapatita en la segunda sesión.

Discusión

Los resultados obtenidos por diferentes autores con el transplante graso autólogo (8-13) han sido muy alentadores; debido a ello hemos tratado patologías de diversos orígenes con fines tanto estéticos como reconstructivos, restaurando por igual pequeños y grandes volúmenes en diferentes regiones corporales y faciales.

El no realizar sobrecorrección del defecto, en contraste con autores que hipercorrigen del $20 \%$ al $50 \%$ (3-6), nos permite poder calcular el resultado de forma más precisa. En la gran mayoría de los casos tratados no fue necesario tener que repetir el procedimiento. Los casos que precisaron más de un tiempo 

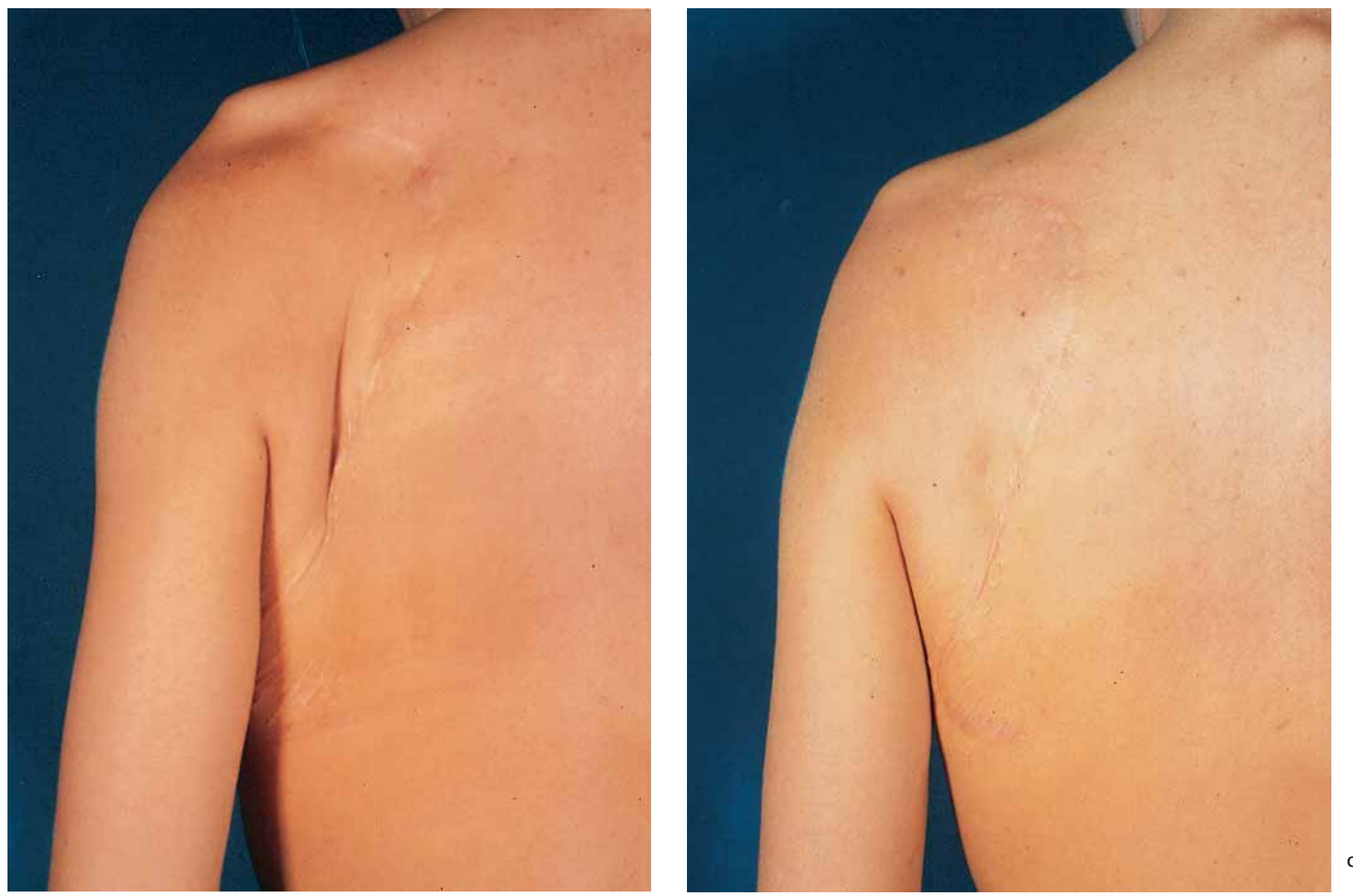

b
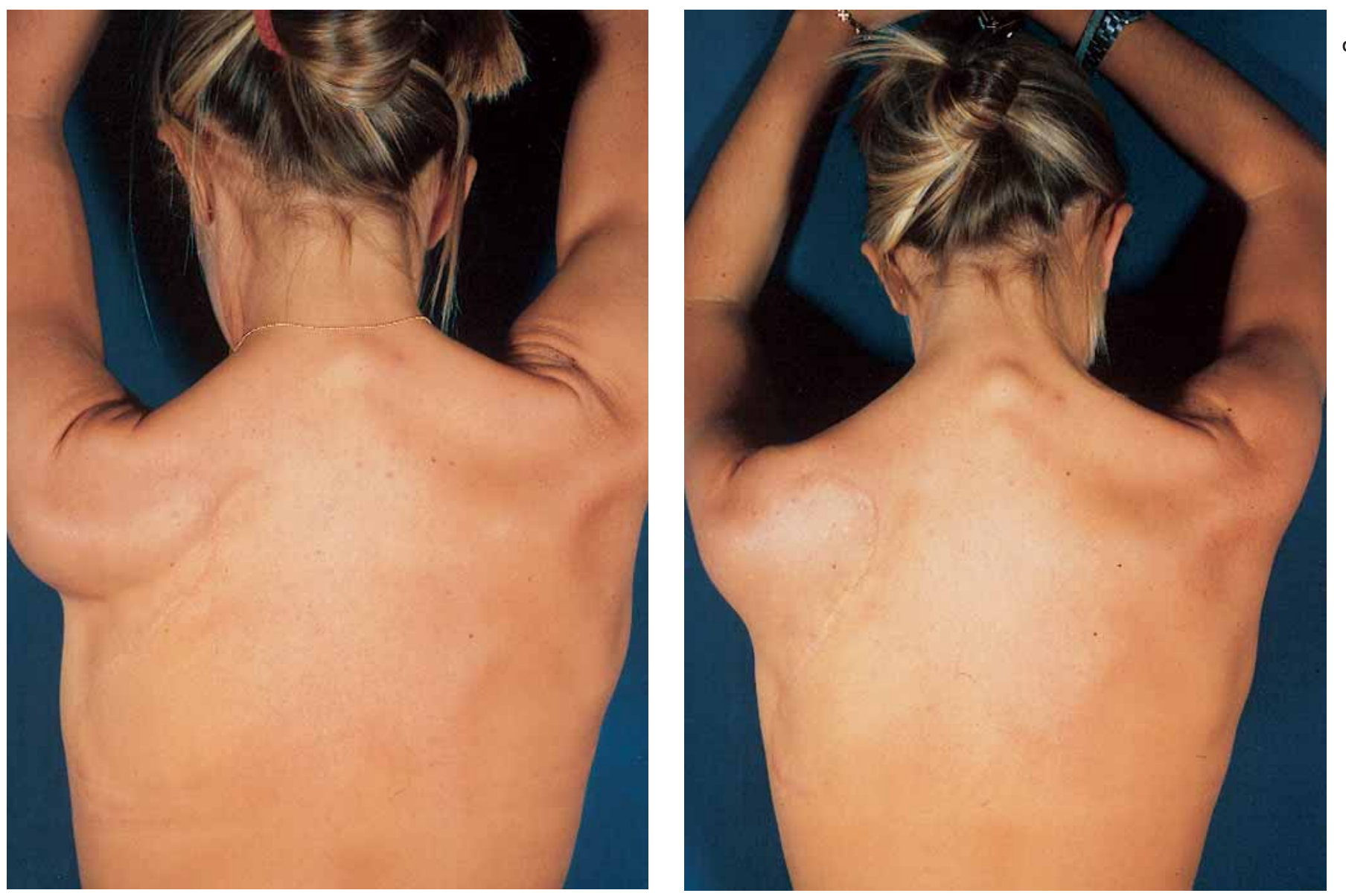

Figura 4. $(a, b)$ Paciente de 26 años de edad con pérdida de sustancia tras resección de músculo dorsal ancho y escápula por carcinoma desmoide juvenil. (c,d): corrección en 3 tiempos con infiltración de 140cc., $70 \mathrm{cc}$. y 12cc.de grasa, pasados 7 años 

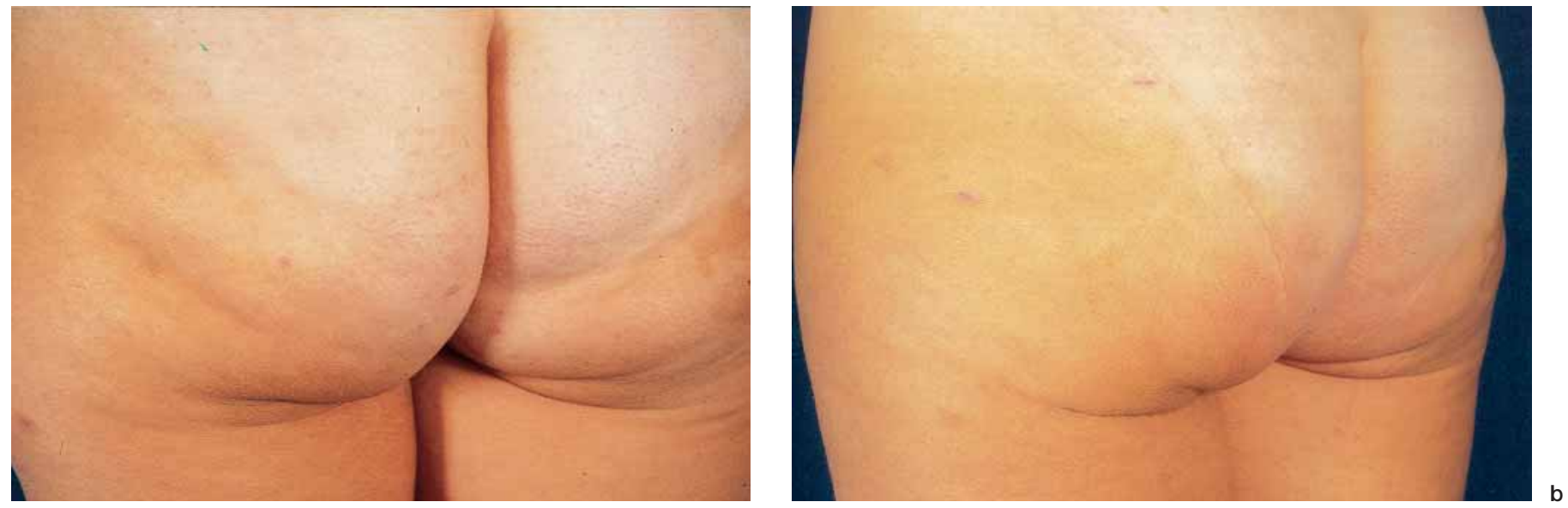

Figura 5. (a) Paciente de 26 años con depresiones glúteas. (b): relleno en una única sesión de lipoestructura, acompañada de liposucción trocantérea ,con una evolución de 7 años.
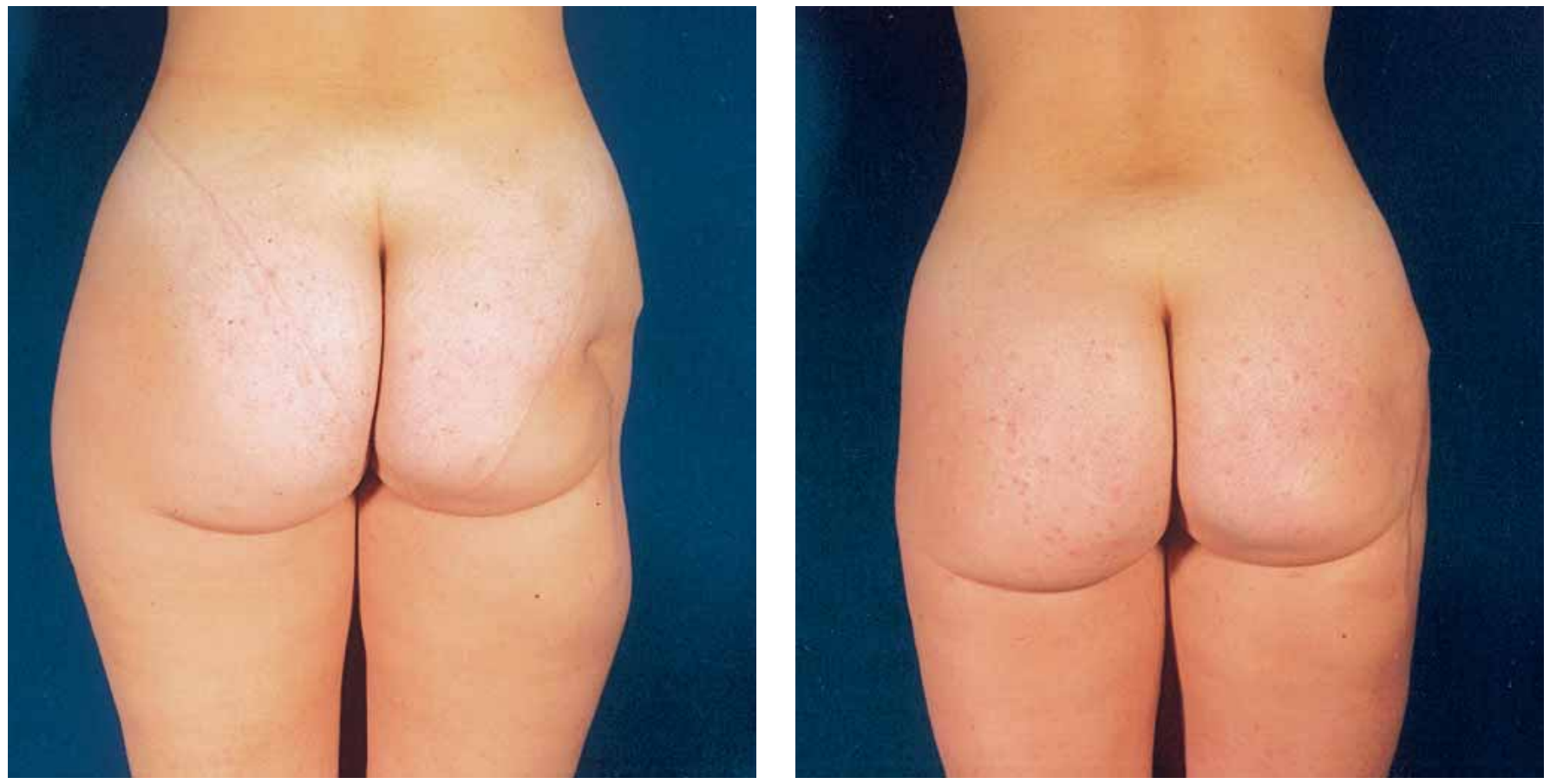

b
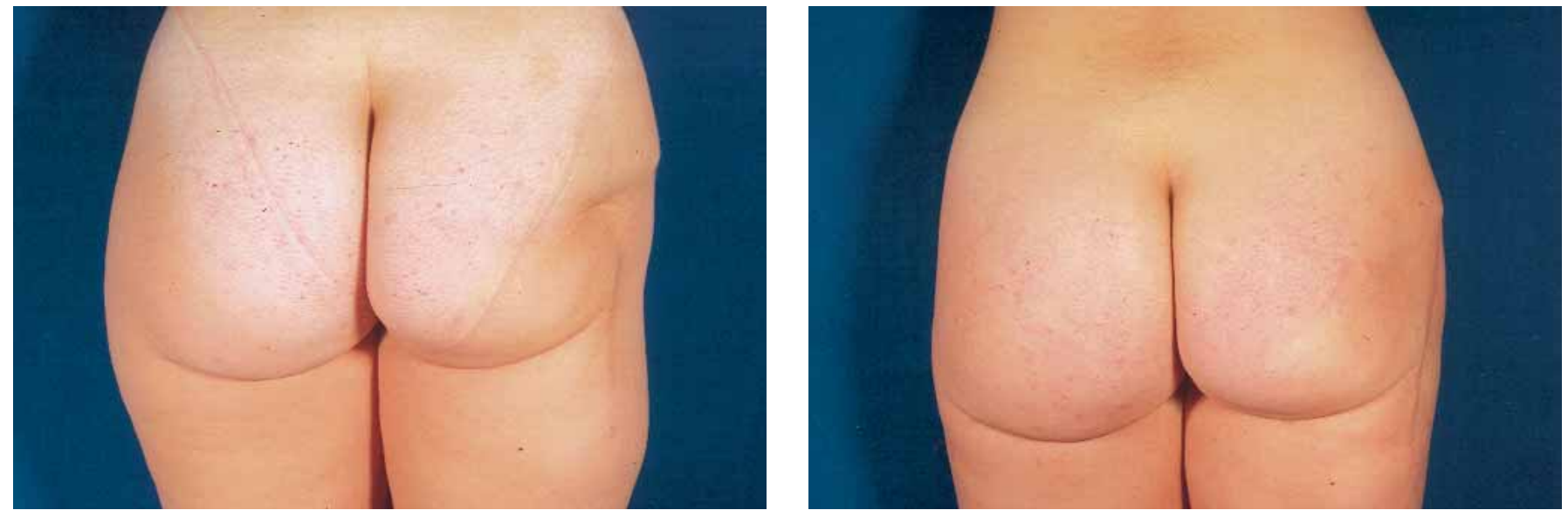

Figura 6. (a, b) Paciente de 25 años con pérdida de sustancia en muslo secundaria a atropello de camión. (c,d): corrección en 3 tiempos ( 270 cc, $150 \mathrm{cc}$ y $50 \mathrm{cc}$ ) mediante lipoestructura a los 5 años de postoperatorio. 
quirúrgico fueron: dos de grandes cantidades de volumen inyectado donde es imposible respetar una mínima distancia de separación entre los filamentos injertados (6) y un caso de depresión del dorso nasal donde el lecho receptor era muy fibroso y con poco aporte vascular, por lo que la viabilidad de supervivencia de la grasa injertada era menor (6).

Dada la versatilidad de la técnica y la permanencia del resultado en el tiempo, creemos que el transplante de tejido graso autólogo cumple con los requisitos para ser el método de elección en el tratamiento de pérdidas de volumen o remodelación volumétrica de distintas regiones corporales y faciales.

\section{Conclusiones}

La lipoestructura nos parece una técnica muy versátil como demuestra la gran variedad de indicaciones quirúrgicas en las que la hemos aplicado. Además incentiva la creatividad del cirujano para seguir ampliando sus indicaciones.

Las principales ventajas de esta técnica son la naturalidad, estabilidad y duración de sus resultados, así como la rápida recuperación del paciente; la ausencia de cicatrices visibles; el gran abanico de indicaciones que tiene el procedimiento y por último la gran ventaja de tratarse de un material autólogo.
Dr. Jorge Planas

C/ Pere de Montcada 16

08034 Barcelona. España

e-mail: jorge@clinica-planas.com

\section{Bibliografía}

1. Neuber F.: "Fettransplantation. Bericht über die Verhandlun gen der Deutschen Gesellschaft für Chirurgie". Zbl Chir, 1893; 22:66.

2. Lexer E.: "Freie Fettransplantation". Dtsch Med Wocheuschr, 1910; 36:640

3. Peer L.A.: "Loss of weight and Volume in Human Fat Grafts". Plast Reconst Surg, 1950; 5:217.

4. Mastudo P.K. and Toledo L.S.: "Experience of Injected Fat Grafiting". Aesth. Plast. Surg, 1988; 12:35.

5. Illouz Y.G.: "Present Results of Fat Injection". Aesth. Plast. Surg, 1988; $12: 175$.

6. Carpaneda C.: "Percentage of Graft Viability Versus Injected Volume in Adipose Autotransplants". Aesth Plast. Surg, 1994; 18:17.

7. Chajchir A.: "Fat Injection: Long-Term Follow Up". Aesth. Plast. Surg, 1996; 20.291.

8. Coleman S.R.: "The Technique of Periorbital Lipoinfiltration". Operative Techniques in Plastic and Reconstructive Surgery, 1994; 1:120.

9. Coleman S.R.: "Long-Term Survival of Fat Transplants: Controlled Demonstrations". Aesth. Plast. Surg., 1995; 19:421.

10. Coleman S.R.: "Facial Recontouring with Lipostructure". Facial Cosmetic Surgery, 1997; 24,2:347.

11. Coleman S.R.: "Structural Fat Grafts". Clinics in Plastic Surgery 2001; 28 (1)

12. Guerrerosantos J.: "Long-Term Survival of Free Fat Grafts in Muscle: A experimental study in rats". Aesth. Plas. Surg., 1996; 20:403.

13. Guerrerosantos J.: "Long term outcome of autologous fat transplantation in aesthetic facial recontouring. Sixteen years of experience with 1936 cases". Clin. Plast. Surg. 200027 (4) 515.

14. Erol O.O: "Facial Autologous Soft-Tissue Contouring by Adjunction of tissue Cocktail injection”. Plast. Reconstr. Surg. 2000 ; 106 (6): 1375.

15. Lewis C.M.: "The Current Status of Autologous Fat Grafiting". Aesth Plast. Surg., 1993; 17:109. 